\title{
Analysis of Tympanometric Attributes in Middle Ear Diseases and in Postoperative Middle Ear Surgeries - A Prospective Study at a Tertiary Hospital in Hyderabad, Telangana
}

\author{
Mohammed Naseeruddin Mujahid ${ }^{1}$, Syeda Ayesha² \\ 1,2 Department of ENT, Deccan College of Medical Sciences and Princess Esra Hospital, Hyderabad, Telangana, India.
}

\section{ABSTRACT}

\section{BACKGROUND}

Tympanometry as a definitive test protocol in the diagnosis of middle-ear disease and function remains still a tentative one. Primarily this is the result of cost effectiveness and concerns over referral to an audiology unit. It was also found to be due to the concerns over variability in test protocols and its influence on demographic and environmental factors. The present study was done to simplify the understanding of the different test variables of tympanometry.

\section{METHODS}

The clinical study was conducted in the Department of ENT, Deccan College of Medical Sciences and Princess Esra Hospital, Hyderabad. Out of 134 patients registered with loss of hearing, 68 patients were grouped as preoperative group (136 ears) and 66 patients as postoperative group (132 ears). The patients in both groups were registered at different times and they were not the same. Audiology equipment used was impedance audiometers (Siemens SD 30, interacoustics AT $235 \mathrm{H}$ ); portable tympanometer (Welch-Allyn). Preliminary pure tone audiometry was also done to supplement the diagnosis. The test results were reported as: conductive, sensorineural, and mixed hearing loss. The results were reported based on the variables/criteria: admittance, tympanometric peak pressure (TPP), peak amplitude (Ya peak) and the volume of the ear canal.

\section{RESULTS}

There were 39 males (57.35\%) and 29 females (42.64\%) in the preoperative group. There were 41 males (62.12\%) and 25 females (37.87\%) in the postoperative group. Middle ear diseases showing conductive deafness were grouped as four types: a) middle ear effusion (35 patients); b) Eustachian tube dysfunction (31 patients); c) Ossicular chain adhesions (38 patients) d) tympanic membrane perforations and tympanosclerosis (28 patients) and e) otosclerosis (02 patients).

\section{CONCLUSIONS}

Using tympanometric attributes such as admittance, tympanometric peak pressure, peak amplitude (Ya peak) and the volume of the ear canal, it was possible to make accurate diagnosis of middle ear diseases and their exact pathology or make a differential diagnosis. The attributes used gave much accurate measure of the mechano-acoustics than the preset values used regularly by many centres.

\section{KEY WORDS}

Impedance Audiometry (Tympanometry), Middle Ear Diseases, Compliance, Peak Pressure and Tympanometric Peak Pressure (TPP)
Corresponding Author: Dr. Mohammed Naseeruddin Mujahid, Assistant Professor, Department of ENT, Deccan College of Medical Sciences and Princess Esra Hospital, Hyderabad, Telangana, India.

E-mail: dr.naseeruddin@yahoo.in

DOI: $10.14260 /$ jemds/2021/774

How to Cite This Article:

Mujahid MN, Ayesha S. Analysis of tympanometric attributes in middle ear diseases and in postoperative middle ear surgeries- a prospective study at a tertiary hospital in Hyderabad, Telangana. J Evolution Med Dent Sci 2021;10(45):38273831, DOI: 10.14260/jemds/2021/774

Submission 04-10-2021, Peer Review 10-11-2021, Acceptance 08-12-2021, Published 11-12-2021.

Copyright (C) 2021 Mohammed Naseeruddin Mujahid et al. This is an open access article distributed under Creative Commons Attribution License [Attribution 4.0 International (CC BY 4.0)] 


\section{BACKGROUND}

Normal middle ear pressure and function depends on eustachian tube (ET) ventilation to a large extent. ${ }^{1}$ Dysfunction of ET causes middle ear diseases; restoration of ET tube function greatly reflects upon the healing and restoration of hearing mechanism following middle ear surgeries. ${ }^{2}$

Preoperative audiological assessment and function of ET tube plays an important role in the prediction of final outcome of the middle ear surgeries. ${ }^{3}$ Middle ear diseases causing hearing loss include chronic adenoiditis, glue ear, acute suppurative otitis media (ASOM or AOM), chronic suppurative otitis media, tympanosclerosis, otosclerosis and ET tube dysfunction. There are different surgeries being used to overcome the pathology of the above mentioned diseases of the middle ear. ${ }^{4}$

Tympanoplasty is one such procedure to eradicate the middle ear disease and to reconstruct the hearing mechanism. ${ }^{5}$ The aims of tympanoplasty are to provide a dry ear and to restore hearing as much as possible.

Many factors have been attributed for the success, out of which ET function is considered one of the most important. ${ }^{6}$ Review of literature showed that the ET tube function is crucial in the success rate of surgeries performed for restoration of hearing loss. ${ }^{7}$

The success rates are higher following tympanoplasty procedures in patients with normal ET function. ${ }^{8}$ And the success rates were lower in patients with ET dysfunction. ${ }^{9}$ Hence accurate preoperative assessment of ET tube function and hearing loss improves the final outcome of by choosing the proper surgical technique for each case. ${ }^{5}$ Certain authors upheld the advantages of tympanometry; an easy procedure, possibility of comparing the data from the different audiology units. ${ }^{10}$

In tympanometry done with standard impedance audiometers, immittance measurement gave few advantages, especially when combined with methods such as a function of the air pressure in the ear canal.11 This function is vital data, influenced by middle ear diseases, and helps in assessing the hearing function accurately. 12

Impedance audiometers measure admittance (compliance) by applying variable pressure in the outer ear canal. In other words, tympanometry is recording the energy of the reflected sound, as the tympanometer is showing the volume of the ear canal. So such data obtained from tympanometry reflects accurately the changes happening in the mechano-acoustic features of the ear function caused by various diseases. ${ }^{13}$

The present study was conducted to assess usefulness of tympanometry in the diagnosis of diseases of the middle ear, focusing on the localization of the pathology and also the final outcome of middle ear surgeries in the follow up period.

\section{Aim of the Study}

To use tympanometric attributes in the diagnosis of various middle ear diseases and use the attributes in the assessment of final outcome of postoperative middle ear surgeries.

\section{Objectives}

To record the attributes like admittance, tympanometric peak pressure, peak amplitude (Ya peak) and the volume of the ear canal in patients with middle ear diseases and post-operative middle ear surgery patients. To analyze the significance of recorded attributes in the diagnosis of middle ear diseases and assessing the final outcome of surgeries of middle ear.

\section{METHODS}

This is a cross sectional, observational and analytical study. 134 patients attending the Department of ENT, Deccan College of Medical Sciences and Princess Esra Hospital were screened preoperatively for evidence of middle ear diseases from January 2017 to December 2018. Middle ear diseases showing conductive deafness were grouped as four types: a) middle ear effusion (35 patients); b) eustachian tube dysfunction (31 patients); c) ossicular chain adhesions (38 patients); d) tympanic membrane perforations and tympanosclerosis (28 patients); and e) otosclerosis (02 patients). 68 patients were subjected to pure tone audiometry and impedance audiometry preoperatively. Another 66 patients who have undergone middle ear surgeries were screened using the pure tone audiometry and impedance audiometry. The instruments used in both the groups were impedance audiometers (Siemens SD 30, Interacoustics AT $235 \mathrm{H}$ ); portable tympanometer (WelchAllyn).

\section{Inclusion Criteria}

1. Patients aged above 8 years and below 68 years.

2. Patients of both genders.

3. Patients with middle ear diseases such as CSOM, ASOM, tympanosclerosis, glue ear and otosclerosis were included.

\section{Exclusion Criteria}

1. Patients below 8 years and above 68 years,

2. Patients with history of tinnitus and loss of equilibrium,

3. Patients with history of diabetes mellitus and hypertension,

4. Patients treated with streptomycin injections,

5. Children with congenital anomalies of the ears were excluded.

\section{Methods}

All the patients were subjected to thorough history taking, ENT examination including otoscopy and oto-endoscopy were done. The audiological examination by impedance audiometry was done. The tympanometry attributes used were: 1 . admittance, 2 . tympanometric peak pressure, 3 . peak amplitude (Ya peak) and 4. The volume of the ear canal in patients with middle ear diseases and post-operative middle ear surgery patients. The volume of the ear canal was measured under conditions of $\mathrm{P}=200 \mathrm{daPa}$. For children, the normal values were taken as between 0.5 to $1.0 \mathrm{ml}$ and for the adults the normal values were 0.6 to $2.0 \mathrm{ml}$. 
Sample Size Calculation

Using the sample size formula

$\mathrm{SS}=\frac{Z 2 P(1-P)}{(C 2)}$

Where,

SS = Sample Size

$\mathrm{Z}=\mathrm{Z}$-Value

$\mathrm{P}=$ Percentage of Population

$\mathrm{C}=$ Confidence interval

The sample size was calculated as 268 .

\section{Statistical Analysis}

Standard statistical methods like, percentage, mean and standard deviation were used.

\section{RESULTS}

Totally 134 patients (268 ears) were subjected to audiological evaluation, among them 68 (136 ears) preoperatively and 66 patients (132 ears) postoperatively. The age, gender distribution was shown in the Table 1 . The youngest patient in the preoperative group was 8 years and the eldest was aged 68 years with a mean age of $37.33 \pm 6.12$ years. The eldest patient in the preoperative group was 11 years and the eldest patient was aged 66 years with a mean age of $39.24 \pm 8.10$ years. There were 39 males (57.35\%) and 29 females (42.64\%) in the preoperative group. There were 41 males $(62.12 \%)$ and 25 females $(37.87 \%)$ in the postoperative group (Table 1). The distribution of provisional diagnosis among the preoperative group patients and the surgeries performed in the post-operative group is tabulated in Table 1.

\begin{tabular}{|c|c|c|c|c|c|}
\hline Observation & $\begin{array}{c}\text { Pre-0p } \\
\text { (68) }\end{array}$ & $\%$ & Observation & $\begin{array}{c}\text { Post-0p } \\
(66)\end{array}$ & $\%$ \\
\hline Age in Years & & & Age in Years & & \\
\hline 8 to 17 & 14 & 20.58 & 8 to 17 & 12 & 18.18 \\
\hline 18 to 27 & 11 & 16.17 & 18 to 27 & 13 & 19.69 \\
\hline 28 to 37 & 23 & 33.82 & 28 to 37 & 25 & 37.87 \\
\hline 38 to 47 & 09 & 13.23 & 38 to 47 & 07 & 10.60 \\
\hline 48 to 57 & 08 & 11.76 & 48 to 57 & 07 & 10.60 \\
\hline 58 to 67 & 03 & 04.41 & 58 to 67 & 02 & 03.03 \\
\hline Gender & & & Gender & & \\
\hline Male & 39 & 57.35 & Male & 29 & 43.93 \\
\hline Female & 42 & 61.76 & Female & 25 & 37.87 \\
\hline Chronic Adenoiditis & 12 & 17.64 & Adenoidectomy & 12 & 18.18 \\
\hline ASOM & 09 & 13.23 & Myringotomy & 09 & 13.63 \\
\hline CSOM & 23 & 33.82 & Tympanoplasty & 23 & 43.93 \\
\hline Tympanosclerosis & 15 & 22.05 & Myringoplasty & 13 & 19.69 \\
\hline Glue Ear & 11 & 16.17 & Ossiculoplasty & 06 & 09.09 \\
\hline \multirow[t]{3}{*}{ Otosclerosis } & 02 & 02.94 & MRM & 04 & 06.06 \\
\hline & & & Grommet & 17 & 25.75 \\
\hline & & & Stapedectomy & 02 & 03.03 \\
\hline $\begin{array}{l}\text { 1. Age, Gend } \\
\text { Study (n - }\end{array}$ & and & (ace & $\begin{array}{l}\text { Surgeries Di. } \\
\text { Post-Operat }\end{array}$ & $\begin{array}{l}\text { ibutio } \\
-66)\end{array}$ & \\
\hline
\end{tabular}

The admittance results obtained from evaluating both the ears of the patients, in both the preoperative and postoperative groups were shown in the Table 2. The total number of ears in the preoperative group tested was 136 and in the postoperative group the ears tested were 132 . The table showed the comparison between both the group of ears with normal and abnormal admittance, counted in number and reflected as a percentage.

\begin{tabular}{|c|c|c|c|c|c|c|}
\hline Admittance & $\begin{array}{c}\text { Pre- } \\
\text { Operative } \\
\text { Ears }\end{array}$ & $\begin{array}{l}\% \text { From } \\
\text { Overall }\end{array}$ & $\begin{array}{c}\text { Post- } \\
\text { Operative } \\
\text { Ears }\end{array}$ & $\begin{array}{l}\text { \% From } \\
\text { Overall }\end{array}$ & Total & $\%$ \\
\hline Abnormalities & 97 & 71.32 & 28 & 21.22 & 125 & 46.64 \\
\hline Normal & 39 & 28.67 & 104 & 78.78 & 143 & 53.35 \\
\hline Total & 136 & 100 & 132 & 100 & 268 & 100 \\
\hline \multicolumn{7}{|c|}{$\begin{array}{l}\text { Table 2. Results of Evaluation of Admittance of Ears of Both the Groups } \\
\text { (n-Pre-Operative - 68, Post-Operative - 66) }\end{array}$} \\
\hline
\end{tabular}

\section{According to Peak Position}

The tympanometric peak pressure measured from all the test ears in the study belonging to both the groups was recorded and presented as follows: No clear peak was recorded in 84 out of total 268 ears (31.34\%). Peak with normal location in 86 out of 268 test ears (32.08\%) was noted abnormal peak location was recorded in 98 total test ears (36.56\%), irrespective of positive and negative zones (Table 3).

\begin{tabular}{|c|c|c|c|c|c|c|c|c|}
\hline \multirow{2}{*}{ TPP } & \multicolumn{3}{|c|}{$\begin{array}{c}\text { Pre-Operative Group } \\
-68\end{array}$} & \multicolumn{3}{|c|}{$\begin{array}{c}\text { Post-Operative } \\
\text { Group - } 66\end{array}$} & \multicolumn{2}{|c|}{ Total } \\
\hline & Ears & $\begin{array}{c}\text { Overall } \\
\%\end{array}$ & $\begin{array}{l}\% \text { of } \\
\text { Group }\end{array}$ & Ears & $\begin{array}{c}\text { Overall } \\
\%\end{array}$ & $\begin{array}{c}\% \\
\text { of Group }\end{array}$ & Nos. & $\%$ \\
\hline Normal & 43 & 16.04 & 31.61 & 41 & 15.29 & 31.06 & 84 & 31.34 \\
\hline Absence & 40 & 14.92 & 29.41 & 46 & 17.16 & 34.84 & 86 & 32.08 \\
\hline $\begin{array}{c}\text { Altered } \\
\text { P+/P- }\end{array}$ & 49 & 18.28 & 36.02 & 49 & 18.28 & 37.12 & 98 & 36.56 \\
\hline Total & 136 & 49.24 & 100 & 132 & 50.73 & 100 & 268 & 100 \\
\hline
\end{tabular}

\section{According to Peak Amplitude}

Static admittance peak (Ya Peak) is defined as the peak value of admittance of the tympanogram. It is measured in miliomes. The data obtained from the ears was interpreted as high, low and unchanged in the two groups of this study (Table 4). The peak amplitude results are shown in the Table 4.

\begin{tabular}{|c|c|c|c|c|c|c|c|c|}
\hline \multirow{2}{*}{$\begin{array}{c}\text { Peak } \\
\text { Amplitude }\end{array}$} & \multicolumn{3}{|c|}{$\begin{array}{l}\text { Pre-Operative } \\
\text { Group-68 }\end{array}$} & \multicolumn{3}{|c|}{$\begin{array}{l}\text { Post-Operative Group- } \\
66\end{array}$} & \multicolumn{2}{|c|}{ Total } \\
\hline & $\begin{array}{c}\text { Ears } \\
136\end{array}$ & $\begin{array}{c}\text { Overall } \\
\%\end{array}$ & $\begin{array}{l}\% \text { of } \\
\text { Group }\end{array}$ & $\begin{array}{c}\text { Ears } \\
132\end{array}$ & $\begin{array}{c}\text { Overall } \\
\%\end{array}$ & $\begin{array}{l}\text { \% of } \\
\text { Group }\end{array}$ & No. & $\%$ \\
\hline Unchanged & 18 & 06.71 & 13.23 & 16 & 05.97 & 12.12 & 34 & 09.23 \\
\hline High & 23 & 08.58 & 16.91 & 19 & 07.08 & 14.39 & 42 & 15.67 \\
\hline Low & 95 & 35.44 & 69.85 & 97 & 36.19 & 73.48 & 192 & 71.64 \\
\hline Total & 136 & 50.73 & 100 & 132 & 49.24 & 100 & 268 & 100 \\
\hline \multicolumn{9}{|c|}{$\begin{array}{l}\text { Table 4. Peak Amplitude Levels in Pre-Operative and Post-Operative } \\
\text { Patients for Comparison (n - Pre-Operative - 68, Post-Operative - 66) }\end{array}$} \\
\hline
\end{tabular}

\section{According to the Volume of the Ear Canal}

The middle ear volume data of both the groups was tabulated in table 5 .

\begin{tabular}{|cccccccccc|}
\hline $\begin{array}{c}\text { Middle } \\
\text { Ear }\end{array}$ & \multicolumn{3}{c}{$\begin{array}{c}\text { Preoperative } \\
\text { Group-68 } \\
\text { Volume }\end{array}$} & $\begin{array}{c}\text { Ears } \\
\text { Overall }\end{array}$ & $\begin{array}{c}\text { \% of } \\
\text { Ears }\end{array}$ & $\begin{array}{c}\text { Eroup-66 } \\
\text { Overall }\end{array}$ & $\begin{array}{c}\text { \% of } \\
\text { Group }\end{array}$ & No. & $\%$ \\
& $\mathbf{1 3 6}$ & $\%$ & Group & $\mathbf{1 3 2}$ & $\%$ & Gotal \\
Normal & 48 & 17.91 & 35.29 & 47 & 17.53 & 35.60 & 95 & 35.44 \\
High & 80 & 29.85 & 58.82 & 26 & 09.70 & 19.69 & 106 & 39.55 \\
Low & 08 & 02.98 & 05.85 & 59 & 22.01 & 44.69 & 67 & 25.00 \\
Total & $\mathbf{1 3 6}$ & $\mathbf{5 0 . 7 4}$ & $\mathbf{1 0 0}$ & $\mathbf{1 3 2}$ & $\mathbf{4 9 . 2 4}$ & $\mathbf{1 0 0}$ & $\mathbf{2 6 8}$ & $\mathbf{1 0 0}$ \\
\hline Table 5. Middle Ear Volumes in Pre-Operative and Post-Operative \\
Patients for Comparison (n-Pre-Operative - 68, Post-Operative - 66) \\
\hline
\end{tabular}




\section{DISCUSSION}

The present study was conducted in patients attending the Department of ENT, Deccan College of Medical Sciences and Princess Esra Hospital, Hyderabad. Audiological evaluation in patients clinically diagnosed with middle ear diseases was done. Similarly audiological evaluation was done using impedance audiometry for the postoperative patients. Both the values of data of both the groups were compared to analyse the accuracy of each variable. Static admittance peak was found to be more accurate as an indicator of middle ear diseases producing conductive deafness instead of comparison to the accepted mean averages preset by the instrument used as observed in the present study (Table 1 and 2 and 3). It helped in registering the pressure in the middle ear accurately and diagnosis of functioning of the eustachian tube. The middle ear pressure represents equal pressure on either sides of the tympanic membrane in the ear canal allowing the conditions for maximum conduction of sound. Whereas the peak values reflect the mobility or density of the eardrum and the middle ear (Table 4). While measuring the middle ear volumes which varied from 0.5 to $2.0 \mathrm{~cm} 3$ or $\mathrm{ml}$ and many of the impedance audiometers have the mean average values preset, it becomes easy and accurate in using these values in addition to the exhaustive metric data from tympanometry (Table 5). The combined results data of pre-operative and post-operative group of patients was undertaken by dividing the patients with conductive hearing loss according to the following criteria: admittance, tympanometric peak pressure, peak amplitude (Ya peak) and the volume of the ear canal. In a similar study by Clyde G Smith Jack L Paradise, Diane L Sabo et al. ${ }^{14}$ they found that tympanograms are usually used to assess the middle ear pathologies. The lower the height and the greater the width of the tympanogram curve, the greater was the probability of associated middle-ear effusion. Its probability was also higher, when peak pressure was negative rather than positive. But their study was in infants below 6 months wherein they found that effusion was diagnosed in only $2.7 \%$ of ears with tympanometric height $>$ or $=0.6 \mathrm{~mL}$, but in 80.2 $\%$ of ears with flat tympanograms. They divided patients into four groups based on the above data; as high, low and unchanged. According to Silman S, Silverman CA, Arick DS et al. ${ }^{15}$ though tympanometry provides diagnostic information on the middle ear sound transmission mechanism, it has three limitations: 1 . Unique tympanometric pattern does not exist for every possible middle ear disorder. 2. Pathology affecting the eardrum (perforation) directly will have the dominant effect on the measured immittance, but the pathology may be inconsequential to the hearing status. 3 . Marked variability exists in tympanometric values. Frequently there would be overlap between the findings in normal and diseased middle ears. In spite of these limitations, Tympanometry when used in combination with otoscopy, PTA and acoustic reflex measurements give valuable augmentative information that would not otherwise be available. Janet Shanks and Jack Shohet ${ }^{16}$ quote in their text book that high positive TPP was also recorded in ears with pinhole perforations of the ear drum (Fowler, Shanks, $2002^{17}$
Kessler et al.18 1998 and Shaw EAG $1974{ }^{19}$ Kobayashi et al. 1987), ${ }^{20}$ To differentiate it, tympanograms with positive TPP should be recorded with descending pressure changes and then again with ascending changes. In a ear with pinhole perforation, TPP from the two pressure sweeps can differ by several hundred daPa in comparison with an expected difference of less than $30 \mathrm{daPa}$ in a normal ear. Hence, recordings of the tympanogram are useful but should be used in of other clinical finding and other complimentary audiological tests.

\section{CONCLUSIONS}

Using tympanometric attributes such as admittance, tympanometric peak pressure, peak amplitude (Ya peak) and the volume of the ear canal, it was possible to make accurate diagnosis of middle ear diseases and their exact pathology or make a differential diagnosis. The attributes used gave much accurate measure of the mechano-acoustics than the preset values used regularly by many centres.

Data sharing statement provided by the authors is available with the full text of this article at jemds.com.

Financial or other competing interests: None.

Disclosure forms provided by the authors are available with the full text of this article at jemds.com.

\section{REFERENCES}

[1] Bluestone CD, Bluestone MB. Eustachian tube: structure, function, role in otitis media. New York: BC Decker 2005:1-9.

[2] Schilder AGM, Bhutta MF, Butler CC. Eustachian tube dysfunction: consensus statement on definition, types, clinical presentation and diagnosis. Clin Otolaryngol 2015;40(5):407-11.

[3] American National Standards Institute (ANSI). American national standards specifications for instruments to measure aural acoustic impedance and admittance /aural acoustic immittance. New York: American National Standards Institute 1987.

[4] Guidelines for screening for hearing impairment and middle-ear disorders. Working group on acoustic immittance measurements and the committee on audiologic evaluation. American Speech-LanguageHearing Association 1990;32 Suppl 2:12-24.

[5] Harris PK, Hutchinson KM, Moravec J. The use of tympanometry and pneumatic otoscopy for predicting middle ear disease. Am J Audiol 2005;14(1):3-13.

[6] Silman S, Silverman CA, Arik DS. Acoustic-immitance screening for detecting for detecting of middle ear effusion in children. J Am Acad Audiol 1992;3(4):262-8.

[7] Kumar N, Madkikar NN, Kishve S, et al. Using middle ear risk index and ET function as parameters for predicting the outcome of tympanoplasty. Indian J Otolaryngol Head Neck Surg 2012;64(1):13-6.

[8] Choi SH, Han JH, Chung JW. Pre-operative evaluation of Eustachian tube function using a modified pressure equilibration test is predictive of good postoperative 
hearing and middle ear aeration in type 1 tympanoplasty patients. Clin Exp Otorhinolaryngol 2009;2(2):61-5.

[9] Callioglu EE, Ceylan BT, Kuran G, et al. Cartilage graft or fascia in tympanoplasty in patients with low middle ear risk index (anatomical and audological results). Eur Arch Otorhinolaryngology 2013;270(11):2833-7.

[10] Holmquist J, Olen L. Evaluation of eustachian tube function. J Laryngol Otol 1980;94(1):15-23.

[11] Todd NW. There are no accurate tests for eustachian tube function. Arch Otolaryngol Head Neck Surg 2000;126(8):1041-2.

[12] Choi SH, Han JH, Chung JW. Pre-operative evaluation of Eustachian tube function using a modified pressure equilibration test is predictive of good postoperative hearing and middle ear aeration in type 1 tympanoplasty patients. Clin Exp Otorhinolaryngol 2009;2(2):61-5.

[13] Sanford CA, Schooling T, Frymark T. Determining the presence or absence of middle ear disorders: an evidence-based systematic review on the diagnostic accuracy of selected assessment instruments. Am J Audiol 2012;21(2):251-68.
[14] Smith CG, Paradise JL, Sabo DL, et al. Tympanometric findings and the probability of middle-ear effusion in 3686 infants and young children. Pediatrics 2006;118(1):1-13.

[15] Silman S, Silverman CA, Arick DS. Acoustic-immittance screening for detection of middle-ear effusion in children. J Am Acad Audiol 1992;3(4):262-8.

[16] Shanks J, Shohet J. Tympanometry in clinical practice. In: A text book of audiology. $5^{\text {th }}$ edn. Shohet Ear Associates Medical Group Inc. Lippincott 2009:157-85.

[17] Fowler CG, Shanks JE. Tympanometry. In: Katz J, ed. Handbook of clinical audiology. Baltimore: Lippincott Williams \& Wilkins 2002:175-204.

[18] Kessler JL, MacDonald CB, Cox LC. Bizarre "sawtooth" tympanogram in a patient with otitis media. J Am Acad Audiol 1998;9(4):272-4.

[19] Shaw EA. Transformation of sound pressure level from the free field to the eardrum in the horizontal plane. J Acoust Soc Am 1974;56(6):1848-61.

[20] Kobayashi T, Okitsu T, Takasaka T. Forward-backward tracing tympanometry. Acta Otolaryn 1987;435:100-6. 